Tohoku J. exp. Med., 1987, 153, 1-4

\title{
A Simple Spectrophotometric Method for the Determination of Thrombin Activity
}

\author{
Kameel Adham Hussein and Jassim M. Al-Hassan \\ Biochemistry Department, Faculty of Science, Kuwait \\ University, Kuwait
}

\begin{abstract}
Hussein, K.A. and Al-Hassan, J.M. A Simple Spectrophotometric Method for the Determination of Thrombin Activity. Tohoku J. exp. Med., 1987, 153 (1), 1-4 The activity of thrombin in commercial preparations was measured by an easy, precise spectrophotometric method that allows determination of thrombin activity in dilute solutions more accurately than other methods hitherto used. The method can also be used to compare fibrinogen content in plasma samples. - thrombin; enzyme; coagulation (plasma)
\end{abstract}

Thrombin activity in commercial preparations is commonly measured in NIH units by visual observation of clotting times. The NIH unit is defined as the amount of enzyme which clots $1 \%$ fibrinogen solution, or plasma with identical reactivity in $15 \mathrm{sec}$, at $37^{\circ} \mathrm{C}, \mathrm{pH} 7.3$ and sodium chloride concentration of $0.154 \mathrm{M}$ (Miale 1977). Other methods determine the thrombin activity by measuring estrolytic action using different substrates (Hough et al. 1964; Rosenberg and Damus 1973). The present report describes the determination of thrombin activity by a simple spectrophotometric method which is superior in precision to currently used procedures.

\section{Materials and Methods}

Veronal-sodium buffer

A $60 \mathrm{mM}$ solution of veronal-sodium buffer at $\mathrm{pH} 7.0$ was prepared by adding $53.6 \mathrm{ml}$ of $0.06 \mathrm{M}$ sodium diethyl-barbiturate to $46.4 \mathrm{ml}$ of $0.06 \mathrm{M} \mathrm{HCl}$. The solution was stored at $5^{\circ} \mathrm{C}$.

Citrated human plasma

Lyophilized human plasma samples, containing $234 \pm 15 \mathrm{mg} / 100 \mathrm{ml}$ fibrinogen, were obtained from "Ortho Diagnostics".

Thrombin preparations

Lyophilized human thrombin preparations were obtained from "Ortho Diagnostics"

Received February 8, 1985; accepted for publication April 10, 1987.

Address for correspondence: Dr. Kameel Adham Hussein, Biochemistry Department, Faculty of Science, Kuwait University, P.O. Box 5969, Kuwait. 
(Raritan, NJ, USA) and Sigma Chemical Co. (St. Louis, MO, USA), and were reconstituted as suggested by the manufacturers. The "Ortho Diagnostics" preparations were stated to contain $50 \mathrm{NIH}$ units of thrombin/ampule (lot 3V279), and were dissolved in $1 \mathrm{ml}$ isotonic saline. The "Sigma" preparations contained $10 \mathrm{NIH}$ units of thrombin/vial (lot 13F, 3954) and were dissolved in $1 \mathrm{ml}$ of deionized water.

Thrombin solutions were further diluted to the required concentrations with deionized water, and were filtered through filter paper to remove suspended particles.

\section{Procedure}

The required volume of dilute thrombin solution was transferred to a small plastic tube. In a similar tube the following solutions were transferred; $1 \mathrm{ml}$ of veronal-sodium buffer, $0.3 \mathrm{ml}$ of plasma and distilled water to complete the volumes in the two tubes to $3.0 \mathrm{ml}$. The tubes were incubated at $37^{\circ} \mathrm{C}$ in a metal heat block. After 5 min, the contents of the two tubes were mixed for $3 \mathrm{sec}$ using a vortex shaker rotated at a low speed, then transferred to a $1 \mathrm{~cm}$ path length cuvette.

The increase in absorbance at $400 \mathrm{~nm}$ was measured using a thermostated LKB digital spectrophotometer (No. 292, Cecil Instruments, Cambridge, England), supplied with a chart recorder. When the determination was done at room temperature $\left(25^{\circ} \mathrm{C}\right)$, the prewarming step was omitted.

\section{RESUlts}

Fig. 1 shows the curves recorded using 0.2 and $1.0 \mathrm{NIH}$ units of thrombin. A tangent was drawn to the linear portion at the beginning of the curve to calculate

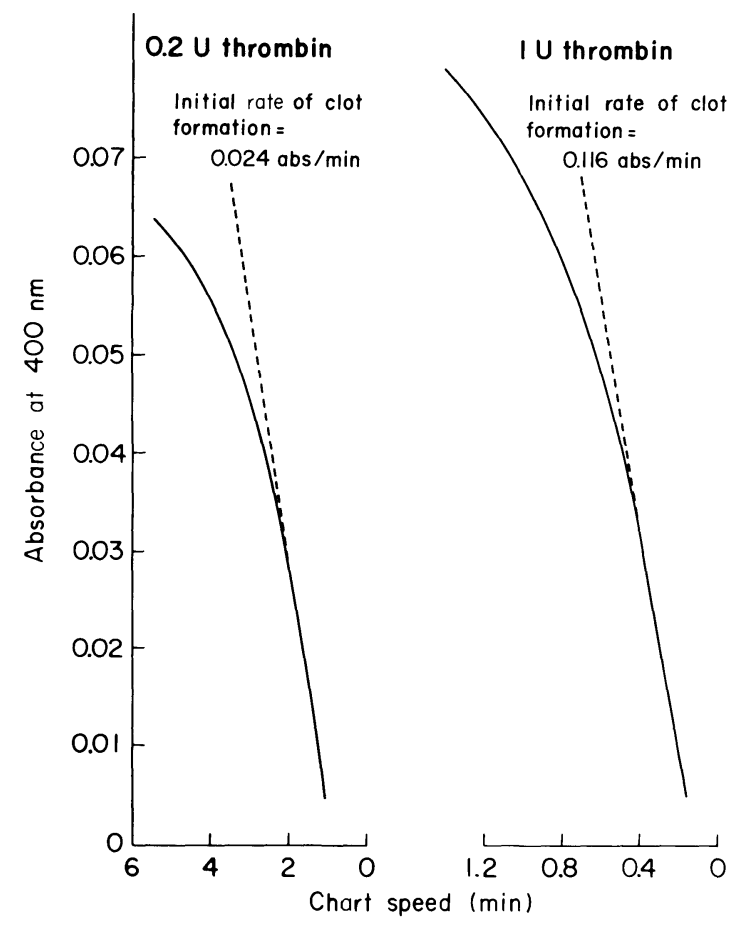

Fig. 1. Chart recorder tracings of plasma coagulated by thrombin. 


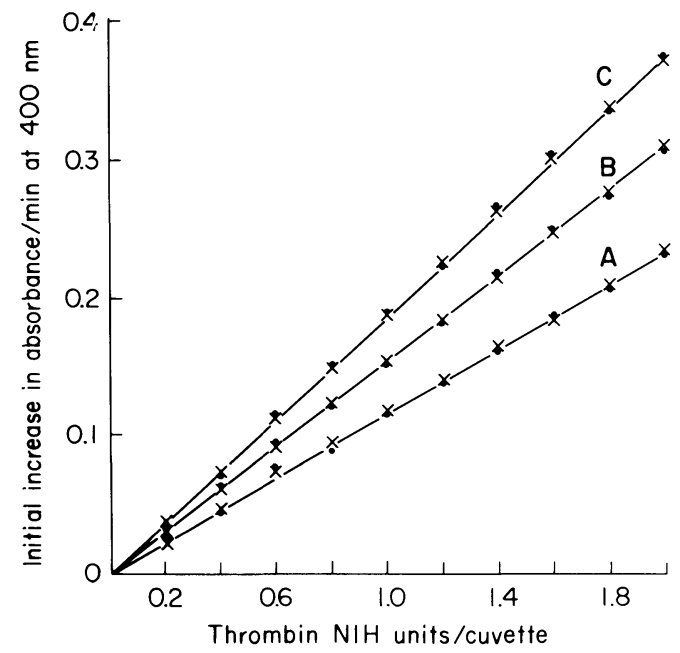

Fig. 2. Effect of increasing thrombin on the initial rate of clot formation. A, "Ortho Diagnostics" thrombin at room temperature; B, at $37^{\circ} \mathrm{C}$; C, "Sigma" thrombin at room temperature.

the initial rate of increase in absorbance. This value is considered to be the initial rate of clot formation.

Fig. 2 shows the effects of concentration of thrombin on the initial increase in absorbance per min during coagulation. Curves 2-A and 2-B represent the "Ortho Diagnostics" thrombin measured at room temperature and at $37^{\circ} \mathrm{C}$, respectively. Curve 2-C represents the "Sigma" thrombin activity determined at room temperature. Each curve was repeated using a different lot of plasma coagulation control.

Fig. 3 shows the initial increase in absorbance per min when the amount of

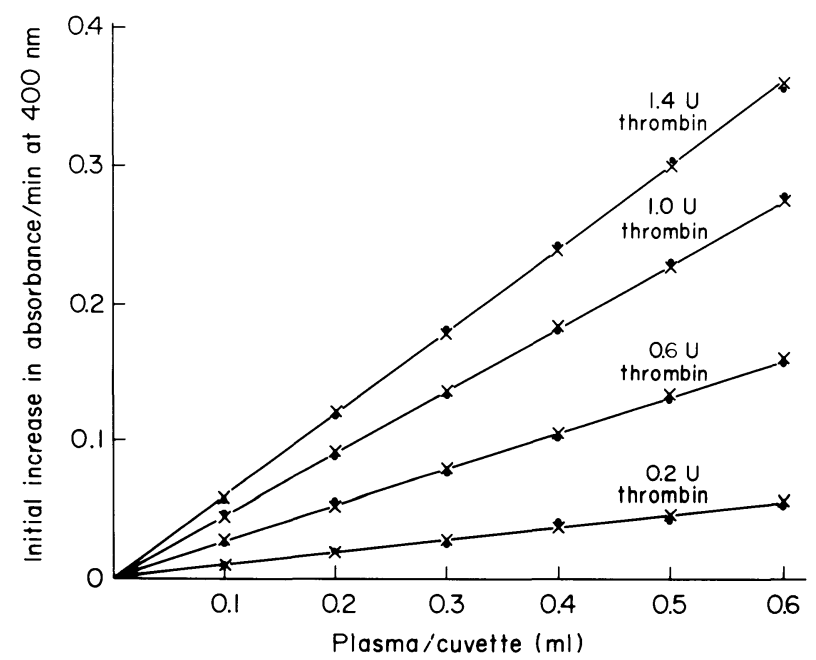

Fig. 3. Effect of increasing plasma on the initial rate of clot formation. 
plasma in the reaction mixture was increased using a constant amount of thrombin (Ortho Diagnostics), at room temperature. Each curve was repeated using a different lot of plasma coagulation control.

\section{Discussion}

The absorbance of 1: 10 diluted solutions of plasma coagulation control was shown to increase rapidly after the addition of thrombin in a reaction medium of $20 \mathrm{mM}$ veronal-sodium buffer, at $\mathrm{pH}$ 7.0. The rate of increase in absorbance at $400 \mathrm{~nm}$ was found to be proportional to the amount of thrombin added. This allows a simple and accurate procedure of thrombin activities in commercial preparations.

Reaction rates at $37^{\circ} \mathrm{C}$ could be precisely measured with amounts of thrombin less than 2.0 NIH units per cuvette. At higher concentration of thrombin, reaction rates became too fast to permit precise tracing. At room temperature, the reaction velocity was decreased to about $75.3 \%$ (Fig. 2).

Results were not affected by changing lots of plasma coagulation control, but different values were obtained when this plasma was substituted with other samples of normal plasma. This is explained by differences in fibrinogen content, since increasing the amount of plasma coagulation control caused a proportional increase in the initial rate of absorbance increase (Fig. 3). The method for thrombin activity assay, therefore, requires fixed levels of fibrinogen in each sample. Data of Fig. 3 show that with constant thrombin levels absorbance changes depend linearly upon fibrinogen content.

The method is easy and can be used for the determination of thrombin activity in different preparations and in dilute thrombin solutions. When the activity of thrombin in the preparation from "Ortho Diagnostics" and "Sigma" were compared the Sigma preparation was $162 \%$ more active when equal number of units were tested (Fig. 2). Moreover, the method can be used for the determination of fibrinogen content in plasma by using thrombin solution of known activity and a reference plasma sample (Fig. 3).

\section{Acknowledgments}

This investigation was supported by Kuwait University Research Council Grant No. SBO 12.

\section{References}

1) Hough, D.A., Lyons, L.V., Koppel, J.L. \& Olwin, J.H. (1964) Spectrophotometric modification of TAMe assay for prothrombin. J. Amer. med. Ass., 188, 207-211.

2) Miale, J.B. (1977) Laboratory Medicine: Hematology, 5th ed., The C.V. Mosby Company, St. Louis, pp. 897.

3) Rosenberg, R.D. \& Damus, P.S. (1973) The purification and mechanism of action of human antithrombin-heparin cofactor. J. biol. Chem., 248, 6490-6505. 